5. Ковалев М.М., Кондрашов В.А. Определение зависимости движущей силы игольчатой бороны от сопротивления почвы проколу и числа одновременно заглубляющихся игл // Texника и оборудование для села. - 2017. - № 6. C. $22-25$.

6. Экспериментальные исследования игольчатой бороны / В.А. Шейченко [и др.]. - Германия, 2017. $164 \mathrm{c}$.
Абрамов Игорь Львович, канд. техн. наук, ведущций научный сотрудник, Федеральный научный иентр лубяных культур, Россия.

170041, г. Тверь, Комсомольский просп., 17/56.

Тел.: (4822) 416-110.

Ключевъе слова: микрорельеф почвы; механическая прочность; расчетная модель; нормальное распределение.

\title{
INVESTIGATION OF THE MICRORELIEF OF THE SOIL LAYER SURFACE AND ITS EFFECT ON THE STRENGTH OF SOIL RESISTANCE TO TILLAGE
}

Abramov Igor Lvovich, Candidate of Technical Sciences, Leading Researcher, Federal Scientific Centerfor Fiber Crops, Russia.

Keywords: soil microrelief; mechanical strength; calculation model; Gaussian distribution.

The lack of the operating elements strength calculating methods providing sufficient accuracy of the results is a significant problem in modern agricultural machinery development. The using calculation models do not take into consideration the microrelief of the treated surface, which leads to a significant error in determining both extreme and long- term loads on the working bodies of mechanisms. In this article author analyzes the cultivated soil treated surface microgeometry influence on the forces arising in the tillage tool. The existing design model is considered on the needle harrow example, its disadvantages are indicated and a way to eliminate them is proposed. Experimental data on the soil surface profile microroughnesses size study are presented, regularities of the microroughnesses random distribution are revealed, in particular, the assumption of the normal nature of this distribution is confirmed. The dependenses based on the obtained data are proposed for a more accurate acting on the tillage tool loads calculation.

\section{СОВЕРШЕНСТВОВАНИЕ КОНСТРУКТИВНЫХ ПАРАМЕТРОВ ШИРОКОЗАХВАТНЫХ ДОЖДЕВАЛЬНЫХ МАШИН КРУГОВОГО ДЕЙСТВИЯ}

\author{
ЖУРАВЛЕВА Лариса Анатольевна, Российский государственный аграрный университет - \\ МСХА имени К. А. Тимирязева
}

НГУЕН Ван Тхуан, Московский политехнический университет

\begin{abstract}
В процессе полива широкозахватными дождевальными машинами (Дм) за счет взаимодействия колес с почвой происходит ее уплотнение. При этом колеса ДМ воздействуют на почву с определенным удельным давлением, зависящим от иелой совокупности факторов, основными из которых являются длина машины, длина пролета, масса машины, диаметр водопроводящего трубопровода, площадъ пятна контакта колеса, определяемого его геометрией, давлением и типом шин. В работе представлены теоретические исследования удельного давления колеса на почву и возможности его снижения. Даны рекомендации по типу и количеству колес, которые необходимо устанавливать на ходовых тележках ДМ на основе сравнения рассчитанного удельного давления конструируемой машины с нормативным воздействием движителей на почву сельскохозяйственной техники.
\end{abstract}

введение. Движение широкозахватных ДМ по орошаемому полю - это процесс взаимодействия их колес с почвой [4], вызывающее ее уплотнение. Интенсивное уплотнение приводит к эрозии почвы, тем самым разрушая природную структуру и уменьшая урожайность. Поэтому совершенствование конструктивных параметров широкозахватных ДМ для удовлетворения требованиям ГОСТ по нормативному удельному давлению на почву является актуальной задачей.
Методика исследований. Расчет был проведен с помощью программы Matlab 2017a.

\section{Расчет для ДМ с пневматическими колесами.}

Исходные данные для расчета: шины марок $14,9-24,16-20,18-24$ и 23-26. Основные характеристики приведены в табл. 1 [8-11].

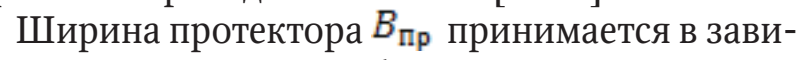
симости от ширины профиля В [1]:

$$
B_{\text {пр }}=(0,7-0,85) B \text {. }
$$


Основные характеристики применяемых шин

\begin{tabular}{|c|c|c|c|}
\hline \multirow{2}{*}{ Тип шин } & \multicolumn{3}{|c|}{ Характеристики } \\
\cline { 2 - 4 } & $\begin{array}{c}\text { Ширина } \\
\text { профиля, дюйм }\end{array}$ & $\begin{array}{c}\text { Посадочный } \\
\text { диаметр, дюйм }\end{array}$ & $\begin{array}{c}\text { Наружный } \\
\text { диаметр, мм }\end{array}$ \\
\hline $14,9-24,0$ & 14,9 & 24 & 1265 \\
\hline $16-20$ & 16 & 20 & 1076 \\
\hline $18-24$ & 18 & 24 & 1400 \\
\hline $23-26$ & 23 & 26 & 1621 \\
\hline
\end{tabular}

Количество тележек $n_{t}$ вычисляется следующим образом:

$$
n_{t}=I N T\left(\frac{L_{\mathrm{M}}}{l_{\text {пр }}}\right)
$$

где $L_{\text {м }}$ - длина машины, м; $l_{\text {пр }}$ - длина пролета, м.

Длину консоли $l_{\text {к }}$ можно выразить следующим образом, м:

$$
l_{\mathrm{k}}=L_{\mathrm{M}}-n_{t} l_{\text {пр }} .
$$

В расчете применяются трубопроводы диаметром 159, 168 и 203 мм. Диаметр консоли соответственно составляет 108, 114 и 133 мм.

Площадь рабочего сечения водопроводящего трубопровода вычисляют следующим образом, м²:

$$
S_{\mathrm{BT}}=\pi \frac{\llbracket\left(d \rrbracket_{\mathrm{BT}}-\Delta d\right)^{2}}{\mathbf{4}},
$$

где $d_{\mathrm{B \tau}}$ - диаметр водопроводящего трубопровода, м; $\boldsymbol{\Delta} d$ - толщина трубы, м.

Площадь рабочего сечения трубы консоли рассчитывают следующим образом, м $^{2}$

$$
S_{\mathrm{K}}=\pi \frac{\llbracket\left(d \rrbracket_{\mathrm{K}}-\Delta d\right)^{2}}{\mathbf{4}},
$$

где $d_{\mathrm{k}}$ - диаметр водопроводящего трубопровода, м.

Объем водопроводящего трубопровода определяют по следующей формуле, $\mathrm{M}^{2}$ :

$$
V_{\mathrm{BT}}=S_{\mathrm{BT}} n_{t} l_{\text {пр }} .
$$

Объем трубы консоли, $\mathrm{M}^{2}$ :

$$
V_{\mathrm{K}}=S_{\mathrm{K}} l_{\mathrm{K}} \text {. }
$$

Массу воды в трубопроводе вычисляют следующим образом, кг:

$$
m_{\mathrm{B}}=1000 k\left(V_{\mathrm{BT}}+V_{\mathrm{K}}\right),
$$

где $k$ - коэффициент наполнения воды, $k=0,7$.

Массу машин без воды определяют по выражению, кг [3]:

$$
m_{\mathrm{M}}=m_{\mathrm{On}}+n_{\mathrm{T}} m_{\mathrm{T}}+m_{\mathrm{ET}}+m_{\mathrm{K}},
$$

где $m_{\text {оп }}$ - масса основной опоры; $m_{\text {т }}$ - масса опорной тележки; $m_{\mathrm{Bт}}-$ масса водопроводящего трубопровода между опорными тележками с системой крепления; $m_{к}$ - масса консоли.
Массу машины с водой рассчитывают следующим образом, кг:

$$
M=m_{\mathrm{M}}+m_{\mathrm{B}} .
$$

Определяем вес, приходящий на каждое колесо, $\mathrm{H}$ :

$$
Q_{\mathrm{k}}=\frac{9,81 M}{2 n_{t}},
$$

Ширина пятна контакта $b_{\mathrm{k}}$ равна ширине протектора $b_{\mathrm{k}}=B_{\text {пр }}$. И длина пятна контакта $a_{\mathrm{k}}$ несколько больше ширины пятна контакта (для узких и обычных шин), и равна или несколько меньше ее (для широкопрофильных шин) [1].

T.e. для шины 14,9-24, 16-20, 18-24: $a_{\mathrm{k}}=1,1 b_{\mathrm{k}}$, а для шины 23-26: $a_{\mathrm{\kappa}}=b_{\mathrm{k}}$.

Площадь пятна контакта вычисляют следующим образом [7]:

для шины 14,9-24, 16-20, 18-24 пятно контакта имеет овальную форму, площадь которой определяют по следующей формуле, $\mathrm{M}^{2}$ :

$$
A=\left(a_{\mathrm{K}}-b_{\mathrm{K}}\right) \cdot b_{\mathrm{k}}+\frac{\pi \mathrm{a}_{\mathrm{k}}^{2}}{4} ;
$$

для шины 23-26 пятно контакта имеет прямоугольную форму, площадь которой определя-

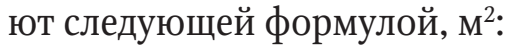

$$
A=a_{\mathrm{\kappa}} b_{\mathrm{\kappa}} .
$$

Отношение ширины шины В к ширине обода $b_{\text {об }}$ не должно превышать 1,5 . В расчете применяется: $\frac{B}{b_{\text {об }}}=1,35$.

Удельное давление одного колеса на почву рассчитывают следующим образом, Па:

$$
\mathrm{P}=\frac{Q_{\mathrm{K}}}{A} .
$$

Нормативные удельные давления на почву представлены в табл. 2 [2]. Рекомендации по количеству колес на одной тележке определены на основе сравнения удельного давления колеса на почву с нормативным удельным давлением. Расчет был проведен для ДМ, на тележке которых устанавливаются два колеса. Если удельное давление на почву по расчету меньше, чем нормативное удельное давление, то на тележке устанавливаются два колеса. Наоборот, если удельное давление на почву по расчету больше, чем нормативное удельное давление, то тележка должна быть трехколесной.

Достоковую норму полива определяют по следующей формуле, м $^{3}$ га [5]:

$$
m_{\text {дост }}=2850\left(1,14-d_{\mathrm{K}}^{2}\right) \cdot \frac{j_{\mathrm{cp}}}{j_{1} K},
$$

где $d_{\mathrm{k}}-$ средний диаметр капель, мм; $j_{\text {ср }}-$ интенсивность дождя, мм/мин; $j_{\mathbf{1}}$ - заданная 
Нормативные удельные давления на почву

\begin{tabular}{|c|c|c|c|c|}
\hline \multirow[t]{2}{*}{ Влажность почвы в слое 0-30 см } & \multicolumn{2}{|c|}{$\begin{array}{c}\text { Максимальное давление на почву } \\
\text { колесного и гусеничного движителей, } \\
\text { кПа, не более }\end{array}$} & \multicolumn{2}{|c|}{$\begin{array}{c}\text { Нормальное напряжение в почве } \\
\text { на глубине 0,5 м, кПа, не более }\end{array}$} \\
\hline & весенний период & летне-осенний период & весенний период & летне-осенний период \\
\hline Свыше 0,9 НВ & 80 & 100 & 25 & 30 \\
\hline 0,7 НВ до 0,9 НВ включительно & 100 & 120 & 25 & 30 \\
\hline 0,6 НВ до 0,7 НВ включительно & 120 & 140 & 30 & 35 \\
\hline 0,5 НВ до 0,6 НВ включительно & 150 & 180 & 35 & 45 \\
\hline 0,5 НВ и меньше & 180 & 210 & 35 & 50 \\
\hline
\end{tabular}

интенсивность дождя, мм/мин; К - коэффициент, учитывающий водопроницаемость почв $(\mathrm{K}=0,6-1,5)$.

Несущую способность почвы после полива можно выразить следующим образом, кПа:

$$
P_{\text {Пп }}=P_{\text {дп }}-\left(1,4 m_{\text {дост }}^{0,65}+8\right),
$$

где $P_{\text {дп }}$ - несущая способность почвы до полива, кПа.

Глубину колеи находят по следующей формуле, м [3, 4]:

$$
H=\frac{0,6 \mathrm{M}}{n_{t} \cdot 10^{3} P_{\text {пп }} b_{\text {об } \sqrt{D_{\mathrm{K}}}}},
$$

где $D_{\text {к }}$ - наружный диаметр колес, м.

Ширину колеи рассчитывают по выражению, м:

$$
\begin{gathered}
B_{\mathrm{\kappa}}=\sqrt{\left(R_{\text {iM }}+\frac{b_{\text {об }}}{2}\right)^{2}+H\left(D_{\mathrm{K}}-\mathrm{H}\right)-} \\
-\left(R_{\text {iм }}-\frac{b_{\text {об }}}{2}\right) .
\end{gathered}
$$

\section{Расчет для ДМ с жесткими колесами}

Ширина и диаметр обода применяемых жестких колес составляют соответственно, м [6]: 0,21 и 0,93.

Длину пятна контакта определяют по следующему выражению, м:

$$
a_{\mathrm{\kappa}}=b_{\mathrm{k}}=b_{\mathrm{06}} \text {. }
$$

Пятно контакта жестких колес имеет прямоугольную форму, площадь которой можно выразить, $\mathrm{M}^{2}$ :

$$
A=a_{\mathrm{r}} b_{\mathrm{\kappa}} .
$$

Остальные параметры вычисляют как для ДМ с пневматическими колесами.

Результаты исследований. Расчет был проведен для ДМ КАСКАД с пневматическими и жесткими колесами для двух типов почв: чернозем обыкновенный и темно-каштановый суглинок.
Результаты расчета для ДМ КАСКАД с пневматическими колесами для почвы чернозем обыкновенный и темно-каштановый суглинок представлены в табл. 3.

Как правило, для полива используют нор-

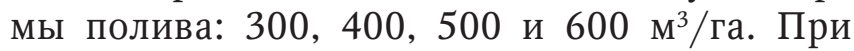
одной норме полива принимаем длины машины: 300, 400, 500, 600 м. При каждой длине машины три длины пролета: 48,7, 59,5, 65,25 м. Для нормы полива $300 \mathrm{~m}^{3} /$ га принимаем шины 14,9-20,0, для нормы полива, и $600 \mathrm{~m}^{3}$ /га принимаем соответственно следующие шины: $14,9-20$ и 16-20, 16-20 и 18-24, $18-24$ и $23-26$.

Из табл. 3 видно, что при одной и той же длине машины, одном диаметре водопроводящего трубопровода и одном типе шин, чем длиннее пролет машины, тем больше вес, приходящийся на колесо, удельное давление на почву и соответственно глубина колеи.

Заключение. По результатам расчета для почв черноземной зоны можно сделать следующие предварительные выводы.

1. При норме полива $300 \mathrm{~m}^{3} /$ га:

для весеннего периода: при длине машины 300 м и длине пролета 65,25 м оптимальным является три колеса на тележке с шинами 14,9-20,0 или два колеса с шинами 16-20;

для летне-осеннего периода: возможно применение на тележке двух колес с шинами 14,9-20,0.

Тогда для использования в течение всего поливного сезона двухколесная тележка с шинами $16-20$.

2. При норме полива $400 \mathrm{~m}^{3} /$ га:

для весеннего периода: при длине машины 300 м и длине пролета 65,25 м оптимальным является три колеса на тележке с шинами $14,9-20,0$ или 16-20, или два колеса с шинами 18-24; при длине машины 400 м и длине пролета 59,5 или 65,25 м оптимальным является три колеса на тележке с шинами 14,9-20,0 или два колеса с шинами 16-20; при длине машины 500 м и длине пролета 59,5 м оптимальным является три колеса на тележке с 
Результаты расчета для ДМ КАСКАД с пневматическими колесами

\begin{tabular}{|c|c|c|c|c|c|c|c|c|c|c|c|c|c|c|}
\hline \multicolumn{3}{|c|}{ Природные условия } & \multicolumn{5}{|c|}{$\begin{array}{c}\text { Характеристики машины КАСКАД } \\
\text { с пневматическими колесами }\end{array}$} & \multicolumn{7}{|c|}{ Рассчитываемые параметры } \\
\hline \multirow[b]{2}{*}{ 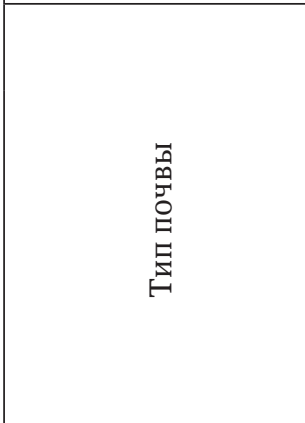 } & \multirow[b]{2}{*}{ 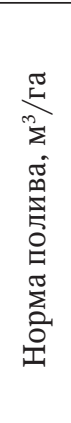 } & \multirow[b]{2}{*}{ 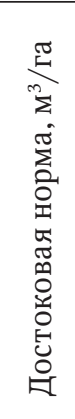 } & \multirow[b]{2}{*}{ 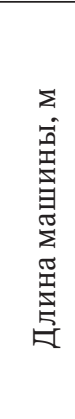 } & \multirow[b]{2}{*}{ 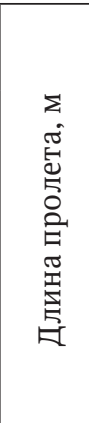 } & \multirow{2}{*}{ 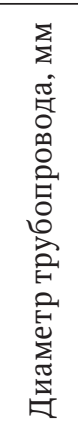 } & \multirow[b]{2}{*}{$\begin{array}{l}\text { 袁 } \\
\text { 具 }\end{array}$} & \multirow[b]{2}{*}{ 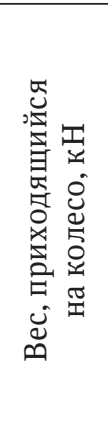 } & \multirow[b]{2}{*}{ 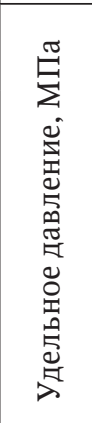 } & \multirow[b]{2}{*}{ 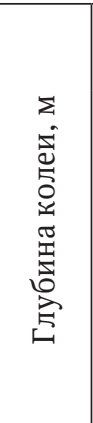 } & \multirow[b]{2}{*}{ 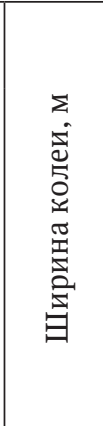 } & \multicolumn{4}{|c|}{$\begin{array}{l}\text { Нормативные удельные } \\
\text { давления, МПа }\end{array}$} \\
\hline & & & & & & & & & & & 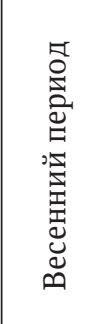 & 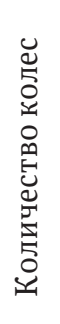 & 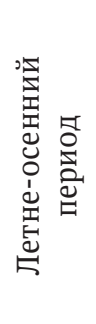 & 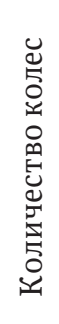 \\
\hline \multirow{12}{*}{$\begin{array}{l}\text { Чернозем } \\
\text { обыкновенный }\end{array}$} & \multirow{12}{*}{300} & \multirow{12}{*}{484} & \multirow{3}{*}{300} & 48,7 & \multirow{12}{*}{159} & \multirow{12}{*}{$14,9-20,0$} & 10,506 & 0,124 & 0,063 & 0,281 & \multirow{12}{*}{0,180} & 2 & \multirow{12}{*}{0,210} & 2 \\
\hline & & & & 59,5 & & & 12,645 & 0,149 & 0,076 & 0,281 & & 2 & & 2 \\
\hline & & & & 65,25 & & & 15,486 & 0,183 & 0,094 & 0,281 & & 3 & & 2 \\
\hline & & & \multirow{3}{*}{400} & 48,7 & & & 10,505 & 0,124 & 0,063 & 0,281 & & 2 & & 2 \\
\hline & & & & 59,5 & & & 13,816 & 0,163 & 0,083 & 0,281 & & 2 & & 2 \\
\hline & & & & 65,25 & & & 14,018 & 0,166 & 0,085 & 0,281 & & 2 & & 2 \\
\hline & & & \multirow{3}{*}{500} & 48,7 & & & 10,505 & 0,124 & 0,063 & 0,281 & & 2 & & 2 \\
\hline & & & & 59,5 & & & 13,084 & 0,155 & 0,079 & 0,281 & & 2 & & 2 \\
\hline & & & & 65,25 & & & 14,856 & 0,176 & 0,09 & 0,281 & & 2 & & 2 \\
\hline & & & \multirow{3}{*}{600} & 48,7 & & & 10,505 & 0,124 & 0,063 & 0,281 & & 2 & & 2 \\
\hline & & & & 59,5 & & & 12,644 & 0,149 & 0,076 & 0,281 & & 2 & & 2 \\
\hline & & & & 65,25 & & & 14,018 & 0,166 & 0,085 & 0,281 & & 2 & & 2 \\
\hline \multirow{3}{*}{$\begin{array}{l}\text { Темно-каштановый } \\
\text { суглинок }\end{array}$} & \multirow{3}{*}{300} & \multirow{3}{*}{629} & \multirow{3}{*}{300} & 48,7 & \multirow{3}{*}{159} & \multirow{3}{*}{$14,9-20,0$} & 10,506 & 0,124 & 0,051 & 0,281 & \multirow{3}{*}{0,180} & 2 & & 2 \\
\hline & & & & 59,5 & & & 12,645 & 0,149 & 0,062 & 0,281 & & 2 & 0,210 & 2 \\
\hline & & & & 65,25 & & & 15,486 & 0,183 & 0,075 & 0,281 & & 3 & & 2 \\
\hline
\end{tabular}

шинами 14,9-20,0 или два колеса с шинами $16-20$, а при длине пролета 65,25 м оптимальным является три колеса на тележке с шинами $14,9-20,0$ или 16-20, или два колеса с шинами 18-24; при длине машины 600 м и длине пролета 65,25 оптимальным является три колеса на тележке с шинами 14,9-20,0 или два колеса с шинами 16-20;

для летне-осеннего периода: при длине машины 300 м и длине пролета 65,25 м оптимальным является три колеса на тележке с шинами 14,9-20,0 или два колеса с шинами 16-20.

3. При норме полива $500 \mathrm{~m}^{3} /$ га:

для весеннего периода: при длине машины 300 м и длине пролета 59,5 м оптимальным является три колеса на тележке с шинами 16-20 или два колеса с шинами 18-24, а при длине пролета 65,25 м оптимальным является три колеса на тележке с шинами 16-20 или $18-24$, или два колеса с шинами 23-26; при длине машины 400 м и длине пролета 59,5 или 65,25 м оптимальным является три колеса на тележке с шинами 16-20 или 18-24, или два колеса с шинами 23-26; при длине машины 500 или 600 м и длине пролета 59,5 м оптимальным является три колеса на тележке с шинами 16-20 или два колеса с шинами
$18-24$, а при длине пролета 65,25 м оптимальным является три колеса на тележке с шинами 16-20 или 18-24, или два колеса с шинами 23-26;

для летне-осеннего периода: при длине машины 300 м и длине пролета 65,25 м оптимальным является три колеса на тележке с шинами 16-20 или 18-24, или два колеса с шинами 23-26; при длине машины 400 или 500 м и длине пролета 59,5 или 65,25 м оптимальным является три колеса на тележке с шинами 16-20 или два колеса с шинами 1824; при длине машины 600 м и длине пролета 65,25 м оптимальным является три колеса на тележке с шинами 16-20 или два колеса с шинами 18-24;

4. При норме полива $600 \mathrm{~m}^{3} /$ га.

для весеннего периода: при длине машины 300 м и длине пролета 48,7 или 59,5 м оптимальным является три колеса на тележке с шинами 18-24 или два колеса с шинами 23-26, а при длине пролета 65,25 м оптимальным является три колеса на тележке с шинами 18-24 или 23-26; при длине машины 400, 500 или 600 м и длине пролета 48,7, 59,5 или 65,25 м оптимальным является три колеса на тележке с шинами 18-24 или два колеса с шинами 23-26; 
для летне-осеннего периода: при длине машины 300, 400, 500 или 600 м и длине пролета 59,5 или 65,25 м оптимальным является три колеса на тележке с шинами 18-24 или два колеса с шинами 23-26.

Если применить жесткие колеса, то оптимальным является три колеса на тележке с ободом ширины 0,21 м.

Аналогичным образом из предлагаемых вариантов решений следует выбирать ходовое оборудование на весь поливной сезон с минимальным воздействием на почву. При этом из экономических соображений, рационально применение двухколесных ходовых систем с более широкопрофильными шинами, нежели трехколесных узкопрофильных.

\section{СПИСОК ЛИТЕРАТУРЫ}

1. Бояркина И.В., Тарасов В.Н. Аналитическое обоснование параметров и норм слойности пневмошин для наземных транспортных средств // Омский научный вестник - 2017. - № 4(154). C. 5-9.

2. ГОСТ 26955-86. Техника сельскохозяйственная мобильная. Нормы воздействия движителей на почву. - М.: Изд-во стандартов, 1986.

3. Журавлева Л.А. Ресурсосберегающие широкозахватные дождевальные машины кругового действия: дис. ... д-ра техн. наук. - Саратов, 2018. - 409 с.

4. Журавлева Л.А., Тхуан Н.В. Уменьшение колееобразования широкозахватных дождевальных машин // Известия МГТУ «МАМИ». - 2020. № 2(44).

5. Каталог. I-Wob Senninger. Дождеватель для механизированного орошения [Электронный ресурс]. - Режим доступа: www.senninger.com - (Дата обращения: 07.03.2021).

6. Машина дождевальная (Фрегат) [Электронный ресурс]. - Режим доступа: https:// www.agrobase.ru/catalog/machinery/machinery fa1666dc-31df-4775-8631-ebc034572b2f (Дата обращения: 02.03.21).

7. Тарасов В.Н., Бояркина И.В., Дегтярь В.В. Метод расчета грузоподъемности пневмоколеса и прочности каркаса автошины транспортного средства // Строительные и дорожные машины. 2015. - № 5. - С. 47-52.

8. Шины, диски и камеры для сельскохозяйственной техники [Электронный ресурс]. - Режим доступа: http://uptire.ru/shiny/1249-shina-149-24128a6-121a8-8-ns-td-19-mitas.html (Дата обращения: 02.03.21).

9. Шины, диски и камеры для сельскохозяйственной техники [Электронный ресурс]. - Режим доступа: http://uptire.ru/shiny/637-shina-16-70-20405-70-20-149b-14-ns-31715806al-in-alliance.html (Дата обращения: 02.03.21).

10. Шины, диски и камеры для сельскохозяйственной техники [Электронный ресурс]. - Режим доступа: http://uptire.ru/shiny/481-shina-184-24158a6-f-148-12-ns-rosava.html (Дата обращения: 02.03.21).

11. Шины, диски и камеры для сельскохозяйственной техники [Электронный ресурс]. - Режим доступа: http://uptire.ru/shiny/294-shina-231-26610-665-152a6-12-ns-ja-242ab-dneproshina.html (Дата обращения: 02.03.21).

Журавлева Лариса Анатольевна, $\partial-p$ техн. наук, доцент кафедры «Организации и технологии строительства объектов природообустройства», Российский государственный аграрный университет МСХА имени К.А. Тимирязева. Россия.

127550, г. Москва, ул. Тимирязевская, 49.

Тел.: +7(917)329-98-12, e-mail:dfz@yandex.ru.

Нгуен Ван Тхуан, аспирант кафедры «Наземные транспортные средства», Московский политехнический университет. Россия.

107023, г. Москва, ул. Большая Семёновская, 38.

Тел.: +7(906) 743-72-87,

e-mail:nguyenthuan230593@gmail.com.

Ключевые слова: норма полива; удельное давление; уплотнение; рекомендации.

\section{THE DESIGN PARAMETERS IMPROVEMENT OF WIDE-GRIP SPRINKLER MACHINES OF CIRCULAR ACTION}

Zhuravleva Larisa Anatolievna, Doctor of Technical Sciences, Associate Professor of the chair "Organizations and Technologies for the Construction of Environmental Facilities”, Russian State Agrarian University - MSHA named after K.A. Timiryazev. Russia.

Nguyen Van Thuan, Post-graduate Student of the chair "Terrestrial Transport Vehicles", Moscow Polytechnic University. Russia.

Keywords: irrigation rate; specific pressure; compaction; recommendations.
During the process of irrigation of wide-coverage sprinklers (WS) by the interaction of the wheels with the soil, the soil is pressed. In this case, the WS wheels impact the soil with a certain specific pressure. Specific pressure depends on a number of factors such as the length of vehicle, span length, vehicle weight, the diameter of water line, wheel contact area, determined by wheel geometry, pressure and tire type. The article carries out theoretical investigations determining the specific pressure of the wheel on the soil. It also given some recommendations connected with a number of wheels to be installed on the WS body compared with the calculated specific pressure of the designed vehicle with the standard specific pressure. 